\title{
Prospects and Challenges of Implementing Cloud Accounting in Bangladesh*
}

\author{
Trina SAHA ${ }^{1}$, Sumon Kumar DAS ${ }^{2}$, Md. Moshiur RAHMAN ${ }^{3}$, \\ Fahimul Kader SIDDIQUE ${ }^{4}$, Mohammad Gias UDDIN ${ }^{5}$
}

Received: September 01, 2020 Revised: October 26, 2020 Accepted: November 05, 2020

\begin{abstract}
The objectives of this study are to understand the meaning of cloud accounting, to investigate whether it is favorable for performance of the organization and what are the challenges if a country like Bangladesh wants to implement it. Primary data have been collected from 300 respondents selected from the field of accounting, such as accountants, accounting graduates of different universities, teachers and bankers. To measure the reliability and validity of the sample size and data, KMO and Bartlett's test have been adopted and the results proved to be reliable and valid for the study. Regression analysis has been done to find out the positive impact of cloud accounting on organizational performance and negative impact of cloud accounting on existing accounting system of the organization. The results of regression analysis supported our alternative hypotheses that cloud accounting can improve organizational performance, but it has also some negative impacts. Descriptive statistics have been used to find out the probable challenges that may be faced by organizations that want to implement it. This is a pioneering study because there is little research on this topic, thus it is expected to develop awareness about cloud accounting in field of accounting in Bangladesh.
\end{abstract}

Keywords: Cloud Accounting, Accounting Software, Organizational Performance, Traditional Accounting System

JEL Classification Code: M15, M41, M49

\section{Introduction}

As we are moving into a new digital age, the popularity of cloud accounting is rapidly increasing. It is changing the

\footnotetext{
*Acknowledgements:

The authors would like to thank the survey participants for their time and valuable responses.

${ }^{1}$ First Author and Corresponding Author. Assistant Professor, Department of Business Administration (DBA), Noakhali Science and Technology University, Bangladesh [Postal Address: Sonapur 3814, Bangladesh] Email: cou.trina00@gmail.com

${ }^{2}$ Assistant Professor, Department of Business Administration (DBA),

Noakhali Science and Technology University, Bangladesh.

Email: sumon30du@gmail.com

${ }^{3}$ Post Graduate, Department of Business Administration (DBA),

Noakhali Science and Technology University, Bangladesh.

Email: moshiurnstu09@gmail.com

${ }^{4}$ Lecturer, Department of Accounting \& Information Systems, Begum

Rokeya University, Bangladesh. Email: fksiddique@yahoo.com

${ }^{5}$ Specialist, Financial Accounting, Sanofi Bangladesh Limited,

Bangladesh. Email: gacnabin@gmail.com

(c) Copyright: The Author(s)

This is an Open Access article distributed under the terms of the Creative Commons Attribution Non-Commercial License (https://creativecommons.org/licenses/by-nc/4.0/) which permits unrestricted non-commercial use, distribution, and reproduction in any medium, provided the unrestricted non-commercial
original work is properly cited.
}

way business organizations are operating as well as manage their financial information. Now organizations do not need to install and maintain software on individual desktop computers, they can access information from remote area having the same version of the software. For those who have discovered and learned to love cloud accounting, they feel as if it has been around forever. Yet, it is a relatively new kid on the block. Despite the fact that the concept of cloud accounting is now a buzzword, the accounting practitioners for all business firms, including small- and medium-sized enterprises in Bangladesh, have to face upcoming challenges to face the technological impact-based Internet. It is a totally a new concept in Bangladesh, but to compete in the global market we should concentrate more on gaining a competitive advantage like developed countries are enjoying. It is believed that, in this modern age, people of all developed countries are benefitting from cloud and its various applications in next decades for official and personal use, while in Bangladesh people are not thinking about the emerging gifts offered by cloud. The primary objective of this paper is to review the initial knowledge of different accounting practitioners and accounting graduate knowledge and opinions on the positive and negative impacts of cloud accounting as well as threats to 
implement it in Bangladesh. Actually, in our country, people of all ages are not so conversant with cloud accounting and there is not enough study about this term. So, there is a need for more studies about cloud accounting to promote cloud accounting in organizations as well as for personal use. The next section reviews the related literature on cloud accounting, followed by research methodology. Findings based on statistical analysis are covered in the fourth section, and the paper concludes with recommendations and further research on cloud accounting.

\section{Literature Review}

Cloud accounting represents the application of accounting that can be accessed from anywhere through an Internet connection. The literature offers many definitions of cloud accounting from different perspectives and degrees. There is confusion between cloud accounting and cloud computing. Mell and Grance (2009) defined cloud computing as a convenient model providing on-demand network access of sharing configurable computing resources, which can be quickly provisioned and requires minimal effort from management and interaction of the service provider. In another study, Mell and Grance (2011) identified some benefits such as improved data safekeeping, improved quality of financial reporting, advanced decision-making process, efficient use of organizational resources, which have been brought by cloud computing to the accounting discipline.

Shkurti and Muca (2014) examined cost saving of hardware and software, reduction in operational cost, and the ability of developing new products as the biggest benefits that can be perceived from implementation of cloud computing and safekeeping, consistency of information, high cost, combination with present accounting system, and policies as the possible barriers to implement cloud computing in an organization. Tarmidi et al. (2014) found, through their study of awareness of cloud computing among accounting practitioners in Malaysia, that, although most of the respondents think cloud computing is an advanced technology of shaping the business process, they are not familiar and not have a clear concept of what cloud-based technology; this has restrained them from enjoying the advancements and benefits offered by the technology.

Ebenezer et al. (2014) tried to find out whether cloud computing can be used in accounting system. They conducted quantitative and qualitative research and, from collecting primary data from accountants and students, they found that $64 \%$ of accountants have enormous knowledge about cloud computing, suggesting that it can be used in accounting process for cost-effectiveness and speed, but $91 \%$ believes that it is not free from security issues regarding data confidentiality. In their impact study of cloud computing on accounting, Gupta and Gaur (2018) recommended to focus on security and reliability factors of cloud computing and not overlooking the human factors at the time of adaptation of cloud technology in accounting system. They suggested that accountants should have in-depth knowledge about cloud technology and not to be solely dependent on cloud service providers for successful implantation of cloud technology.

Mishra and Mohanty (2017) have defined cloud accounting as online accounting, which acts like an application software on users computers, but offers services via Internet and allow access to users from remote servers. They also think cloud-based software is a threat for those who are not interested to implement it and also not ready to realize the benefits of cloud software.

Ali and Thakur (2017) suggested the awareness importance of cloud-based accounting that focus should be put on chartered accountants, as they are involved in internal and external advisory services related with accounting system of an organization. They found that most of the chartered accountants are not using cloud accounting because of the security of losing data, and the extra cost of migration from traditional accounting to cloud accounting. Yoo and Kim (2018) identified the factors of cloud computation such as task characteristics, technology characteristics, organizational factors and environmental factors, and their impacts and inter-relationships.

Tulsian (2012) studied the implications of cloud accounting for small businesses and suggested companies should use cloud accounting in order to transform client relationship by improved collaboration and communication, which will help them to eliminate the problem of transmitting data back and forth. A vital role can be played by accountants in learning new insights on technology, which can renovate the performance of businesses. To minimize repetitive administrative process and fees given to qualified human resource for their expertise and knowledge, accounting professionals should adapt with the new technology and also find a new ways of working in the digitalized world. In this journey technology and cloud model can make it easy, simple and affordable for them.

To become competent with new technology accounting graduates need to be educated from the very beginning of their study life. Aryanti and Adhariani (2020) found learning about work ethics, teamwork, time management skills, and knowledge of financial statement analysis, Microsoft office program, and attending different curricular activities are important for the accounting students to pursue their career. Alimbudiono (2020) suggested to focus on accounting knowledge to increase the competence to be a qualified public accountant and attitude as a notable factor.

Dimitru and Matei (2014) conducted a qualitative research based on the literature on cloud accounting. They reviewed these technologies from business and accountant's perspectives and found that the popularity of the cloud 
concept is increasing day by day and, interestingly, more companies are adopting cloud-based software to enjoy the benefits and advancements offered by it. It has opened access to updated financial data via the Internet to all business participants as well as potential users.

Bangladesh being a newcomer in cloud accounting practices, there is not enough research conducted in this area. To make Bangladesh a digital market requires more research in this sector. Khanom (2017) provided a theoretical overview on cloud accounting from the information that has been collected and organized from the most recent studies conducted by accounting professionals and experts. She has cleared the concept of cloud, its importance in accounting, the reasons of using it, suitability and risk, myths related with security, control and cost of cloud technology, and drawbacks of implementing cloud technology.

Sobhan (2019) provided a framework that can be implemented in the adoption of cloud accounting in Bangladesh. He suggested that cloud accounting should be adopted by organizations to encourage startups, foster innovation and employment as well as boost the governmental system of Bangladesh. Concerned authorities should take initiatives to change and improve the perception of people regarding cloud accounting, students in the field of accounting, and people engaged in several accounting related activities should be educated and trained about cloud technology.

Islam et al. (2015) discussed some advantages and drawbacks of cloud technology in Bangladesh. They proposed a framework for cloud adoption comprising of four steps: feasibility study, planning, implementation, and renewal. For each step, they proposed some suggestions, which can be used as a guide for organizations and industries that are willing to adopt cloud technology. They also suggested to solve the problems of cloud technology and to reach agreements with cloud service providers before they is massively adopted by users.

\section{Research Methodology}

\subsection{Research Problem}

Cloud accounting as a tool of accounting is no longer speculation, it is now reality. The accounting world is changing drastically with the introduction of cloud. It has made information accessible anytime from anywhere, in a secured and sustainable fashion. Although it is used by many organization, very few people know the exact concept of cloud accounting. Some people confused cloud accounting and cloud computing, some think it as a mere accounting software where cloud accounting is using Internet to store data rather than saving data on a hard drive. In Bangladesh, it is a totally a new concept. There are a number of studies on accounting software, but no concrete research focuses on cloud accounting until now. So, there is a research gap that is the basis for this research to find out the advancement of cloud accounting as well as prospects and challenges of implementing it in a developing country like Bangladesh.

\subsection{Research Objectives}

The core objective of this report is to assess the knowledge of accounting practitioners as well as accounting graduates about cloud accounting, and prospects and challenges to implement cloud accounting in Bangladesh related to modern accountancy. The specific objectives of this research are:

i. To ascertain the positive impact of cloud accounting on organizational performance.

ii. To ascertain the negative impact of cloud accounting on traditional accounting system.

iii. To ascertain the challenges and threats of cloud accounting implementation.

\subsection{Sample and Method of Data Collection}

This study has been conducted through primary data collection. Primary data have been collected from the sample size of 300 respondents using convenience sampling method through questionnaire survey. A 5-point Likert scale, from 1 "Strongly Disagree" to 5 "Strongly Agree", is used with a set of statements in the questionnaire. The target population was chartered accountants, university teachers, accounting graduates from different public and private universities, accounting officers related with banking activities, and insurance officers. Data collection has been conducted from May to July 2020.

\subsection{Development of Hypotheses}

From the review of associated literature the following hypotheses can be formulated with respect to research problem and research objectives set above:

H1: Cloud accounting has a positive impact on organizational performance.

H2: Cloud accounting has some negative impact on traditional accounting system of an organization.

\subsection{Variables and Data Analysis Tools of the Study}

This study examines the prospects and challenges of implanting cloud accounting in Bangladesh. Cloud accounting is the independent variable and organizational performance and traditional accounting system are two dependent variables to test our hypotheses. The dependent variables are tested on the basis of some key factors. Analyses are done using SPSS to fulfill our research objectives. 


\section{Results and Discussion}

\subsection{Reliability Statistics}

Internal consistency, that is how closely related a set of items is as a group, is measured by Cronbach's Alpha. In the following table the value is .838 with all 19 items together which is greater than .80 , indicating relatively high internal consistency. Thus, it can be safely concluded that the reliability of this study is substantial in every respects because the sample size as well as collected data are reliable.

\subsection{Demographic Profile}

From demographic information about respondents we see more that $51 \%$ of the respondents were male and $48.7 \%$ were female. Most of the participants of this survey were young people, comprising $84.3 \%$ of total respondents. And it was also found that most of the respondents were postgraduates from different universities, comprising of $55.7 \%$ of total respondents.

\subsection{Testing of Hypothesis 1}

Here our null and alternative hypotheses are:

$\mathbf{H}_{0}$ : There is no impact of cloud accounting on organizational performance.

$\mathbf{H}_{1}$ : Cloud accounting has a positive impact on organizational performance.

\subsubsection{Validity Analysis}

$\mathrm{KMO}$ is a measure of suitability of data for factor analysis. It is used to determine the sampling adequacy of data. Table 2 displays the Kaiser-Meyer-Olkin value of .754 , which is more than 0.7, indicating that data are suitable for research study. In Bartlett's Test of Sphericity the significance level is less than 0.05, which indicates the result is valid. The approximate Chi-Square is 1524.915 with 78 degree of freedom, which is greater than the table value. This leads us to reject the null hypothesis that the population correlation matrix is an identity matrix. So, it can be said that samples are not from population with equal variance. Therefore, the KMO and Bartlett's Test of Sphericity ,significant.

\subsubsection{Regression Analysis}

Regression analysis has been used to examine the impact of cloud accounting on organizational performance, the following tables exhibit the results of the regression analysis. To predict the goodness-of-fit of the regression model, the multiple correlation coefficient (R), square multiple correlation coefficient $\left(\mathrm{R}^{2}\right)$, adjusted $\mathrm{R}^{2}, \mathrm{~F}$ ratio and $\mathrm{t}$-values with significance have been examined.
Table 1: Reliability Statistics

\begin{tabular}{|l|c|}
\hline Cronbach's Alpha & N of Items \\
\hline .838 & 19 \\
\hline
\end{tabular}

Table 2: KMO and Bartlett's Test

\begin{tabular}{|l|l|c|}
\hline \multicolumn{2}{|l|}{$\begin{array}{l}\text { Kaiser-Meyer-Olkin Measure of } \\
\text { Sampling Adequacy. }\end{array}$} & .754 \\
\hline $\begin{array}{l}\text { Bartlett's Test } \\
\text { of Sphericity }\end{array}$ & Approx. Chi-Square & 1524.915 \\
\cline { 2 - 3 } & Df & 78 \\
\cline { 2 - 3 } & Sig. & .000 \\
\hline
\end{tabular}

Table 3 shows the regression analysis results. To determine the goodness-of-fit of the regression model, the multiple correlation coefficient $(\mathrm{R})$ represents the absolute value of coefficient correlation. Here the value is .668 , which indicates a moderate degree of positive correlation. $\mathrm{R}$ square of the regression is the fraction of the variation dependent variable predicted by independent variable. The result of $\mathrm{R}$ square is .446 , which means that approximately $45 \%$ of the variation is the dependent variable, i.e., organization performance is explained by the independent variable cloud accounting. The adjusted $\mathrm{R}^{2}$ value of .423 is ideal to generalize the model because this value is very close to $\mathrm{R}$ square with a small difference of .023 (.446-.423). This means that, if the model were applied to the population, there would be a lower variance of $2.3 \%$ in the outcome.

ANOVA reports how well the regression analysis fits the data. Here, the most interesting column is the significance column. This indicates the statistical significance of the regression model. Here $\mathrm{P}$ is less than 0.0005 , which is less than 0.05 , indicating the model statistically significantly predicts the outcome. The F ratio is highly substantial and this means that the model significantly improves the ability to predict the outcome variable and best fits the population from which the data were sampled. Thus, the regression model achieved a satisfactory level of goodness-of-fit in predicting the variance as measured by above mentioned $\mathrm{R}$, $\mathrm{R}$ square, Adjusted $\mathrm{R}$ square and $\mathrm{F}$ ratio.

The values of $\mathrm{B}$, Beta and $\mathrm{t}$ in the regression analysis means that, for every one unit change in independent variables, the dependent variable would be affected by the same unit. For example, every unit change in modern technology would affect organizational performance by $35 \%$. The beta coefficient is used to explain the relative importance of dependent variables in contributing independent variable. The variables with smaller significant value and greater $t$ value make the greater contribution to the dependent variable. 
Table 3: Regression Analysis of $\mathrm{H} 1$

\begin{tabular}{|c|c|c|c|c|c|c|c|}
\hline \multicolumn{8}{|c|}{ Model Summary } \\
\hline \multicolumn{2}{|c|}{ Model } & $\mathbf{R}$ & \multicolumn{2}{|c|}{ R Square } & Adjusted R Square & \multicolumn{2}{|c|}{$\begin{array}{l}\text { Std. Error of the } \\
\text { Estimate }\end{array}$} \\
\hline \multicolumn{2}{|c|}{1} & $.668^{a}$ & \multicolumn{2}{|r|}{.446} & .423 & \multicolumn{2}{|c|}{.53745} \\
\hline \multicolumn{8}{|c|}{ ANOVA $^{a}$} \\
\hline \multicolumn{2}{|c|}{ Model } & Sum of Squares & df & Mean Square & $\mathbf{F}$ & \multicolumn{2}{|c|}{ Sig. } \\
\hline \multirow[t]{3}{*}{1} & Regression & 66.736 & 12 & 5.561 & 19.253 & \multicolumn{2}{|c|}{$.000^{\mathrm{b}}$} \\
\hline & Residual & 82.901 & 287 & .289 & & & \\
\hline & Total & 149.637 & 299 & & & & \\
\hline \multicolumn{8}{|c|}{$\begin{array}{l}\text { a. Predictors: (Constant), Greater security, Improves knowledge, Reliable information, Quality of decision, Greater storage capabilities, } \\
\text { Consistency of data, Improved services, Keep pace with the modern technology, Accessibility of financial information, Quick operations } \\
\text { management, Cost effectiveness }\end{array}$} \\
\hline \multicolumn{8}{|c|}{ Coefficients $^{a}$} \\
\hline \multirow{2}{*}{\multicolumn{3}{|c|}{ Model }} & \multicolumn{2}{|c|}{ Unstandardized Coefficients } & $\begin{array}{l}\text { Standardized } \\
\text { Coefficients }\end{array}$ & \multirow[t]{2}{*}{$\mathbf{t}$} & \multirow{2}{*}{ Sig. } \\
\hline & & & B & Std. Error & Beta & & \\
\hline \multirow[t]{12}{*}{1} & \multicolumn{2}{|l|}{ (Constant) } & -.670 & .389 & & -1.724 & .086 \\
\hline & \multicolumn{2}{|c|}{$\begin{array}{l}\text { Keep pace with the modern } \\
\text { technology }\end{array}$} & .350 & .078 & .295 & 4.494 & .000 \\
\hline & \multicolumn{2}{|c|}{ Cost effectiveness } & .127 & .075 & .133 & 1.699 & .090 \\
\hline & \multicolumn{2}{|c|}{ Quick operations management } & .046 & .072 & .045 & .633 & .527 \\
\hline & \multicolumn{2}{|c|}{ Accessibility of financial information } & .067 & .070 & .056 & .961 & .337 \\
\hline & \multicolumn{2}{|c|}{ Reliable information } & .009 & .055 & .008 & .159 & .874 \\
\hline & \multicolumn{2}{|c|}{ Consistency of data } & .072 & .059 & .062 & 1.217 & .225 \\
\hline & \multicolumn{2}{|c|}{ Greater storage capabilities } & .072 & .053 & .076 & 1.351 & .178 \\
\hline & \multicolumn{2}{|c|}{ Quality of decision } & .030 & .065 & .028 & .470 & .639 \\
\hline & \multicolumn{2}{|c|}{ Improved services } & .209 & .082 & .151 & 2.542 & .012 \\
\hline & Improves knowle & & .021 & .062 & .026 & .334 & .738 \\
\hline & Greater security & & .191 & .062 & .171 & 3.088 & .002 \\
\hline
\end{tabular}

In summary, it can be said that all fundamental magnitudes are positive and significant. Thus, the result of the regression analysis rejects the null hypothesis that "There is no impact of cloud accounting on organizational performance" and accepts the alternative hypothesis that "Cloud accounting has a positive impact on organizational performance".

\subsection{Testing of Hypothesis 2}

Here our null and alternative hypotheses are:

$\mathbf{H}_{\mathbf{0}}$ : There is no impact of cloud accounting on the accounting system of an organization .
$\mathbf{H}_{\mathbf{1}}$ : Cloud accounting has some negative impact on traditional accounting system of an organization.

\subsubsection{Validity Analysis}

A thumb rule of $\mathrm{KMO}$ test is that value between 0.60-0.69 is average. Here, the value of .647 indicates that the data are moderately suitable for study. In Bartlett's Test of Sphericity, the significance level is less than 0.05 , which indicates that the result is valid. The approximate Chi-Square is 364.842 with 15 degree of freedom, which is greater than the table value. This leads us to reject the null hypothesis that the population correlation matrix is an identity matrix. 


\subsubsection{Regression Analysis}

In Table 5, the value is .629 , which indicates a moderate degree of correlation. The result of $\mathrm{R}$ square is .396, which means that only $39 \%$ of the variation is dependent variable, that is, traditional accounting system is explained by independent variable, cloud accounting. There would be a lower variance of $1 \%$ in the outcome if the model were applied to the population.

In Table 5, P is less than 0.0005 , which is less than 0.05 , indicating the model statistically significantly predicts the outcome and the F ratio is highly significant. Thus, we can say the regression model achieved a satisfactory level of goodness-of-fit in predicting the variance.

We see that all of the values of independent variable have a positive relationship with dependent variables. That means, for each unit change in operational expenses accounting system changes by $15.6 \%$. The variables with smaller significant value and greater $\mathrm{t}$ value make the greater contribution to the dependent variable. From all dimensions, our findings rejects the null hypothesis "There is no impact of cloud accounting on accounting system of an organization" and accepts the alternative hypothesis "Cloud Accounting has some negative impact on traditional accounting system of an organization".

Table 6 shows that in Bangladesh, people are not so knowledgeable about the term "cloud accounting," and migration from traditional systems to cloud-based technology is more complex; these are the major threats to implement cloud accounting in Bangladesh. Besides, enough responses identified the lack of accessible high speed internet to be able to use cloud accounting as a threat, and few people thought about using cloud accounting; the rest of the respondents agreed about the fear hackers accessing personal data, thus, increasing cost.

Table 4: KMO and Bartlett's Test

\begin{tabular}{|l|c|c|}
\hline Kaiser-Meyer-Olkin Measure of Sampling Adequacy. & $\mathbf{. 6 4 7}$ \\
\hline Bartlett's Test of Sphericity & Approx. Chi-Square & 364.842 \\
\hline & Df & 15 \\
\hline & Sig. & .000 \\
\hline
\end{tabular}

Table 5: Regression Analysis of $\mathrm{H} 2$

\begin{tabular}{|c|c|c|c|c|c|c|c|}
\hline \multicolumn{8}{|c|}{ Model Summary } \\
\hline \multicolumn{2}{|c|}{ Model } & \multicolumn{2}{|l|}{$\mathbf{R}$} & R Square & Adjusted R Square & \multicolumn{2}{|c|}{ Std. Error of the Estimate } \\
\hline \multicolumn{2}{|l|}{1} & \multicolumn{2}{|l|}{$.629^{\mathrm{a}}$} & .396 & .386 & \multicolumn{2}{|c|}{.58355} \\
\hline \multicolumn{8}{|c|}{ ANOVA $^{\mathrm{a}}$} \\
\hline \multicolumn{2}{|c|}{ Model } & \multicolumn{2}{|c|}{ Sum of Squares } & Df & Mean Square & $\mathbf{F}$ & Sig. \\
\hline \multirow[t]{3}{*}{1} & Regression & \multicolumn{2}{|c|}{65.632} & 5 & 13.126 & 38.548 & \multirow[t]{2}{*}{$.000^{\mathrm{b}}$} \\
\hline & Residual & \multirow{2}{*}{\multicolumn{2}{|c|}{$\begin{array}{l}100.114 \\
165.747\end{array}$}} & 294 & .341 & & \\
\hline & Total & & & 299 & & & \\
\hline \multicolumn{8}{|c|}{ a. Dependent Variable: Traditional accounting System } \\
\hline \multicolumn{8}{|c|}{$\begin{array}{l}\text { a. Predictors: (Constant), Challenging implementation, Operational expenses, More complex, Chance of losing data, Special skills and } \\
\text { knowledge }\end{array}$} \\
\hline \multicolumn{8}{|c|}{ Coefficients $^{a}$} \\
\hline \multirow{2}{*}{\multicolumn{3}{|c|}{ Model }} & \multicolumn{2}{|c|}{ Unstandardized Coefficients } & $\begin{array}{l}\text { Standardized } \\
\text { Coefficients }\end{array}$ & \multirow[t]{2}{*}{$t$} & \multirow[t]{2}{*}{ Sig. } \\
\hline & & & B & Std. Error & Beta & & \\
\hline \multirow[t]{6}{*}{1} & \multicolumn{2}{|l|}{ (Constant) } & -.509 & .343 & & -1.483 & .139 \\
\hline & Operational e & ses & .156 & .057 & .141 & 2.722 & .007 \\
\hline & Special skills & knowledge & .263 & .069 & .227 & 3.795 & .000 \\
\hline & More complex & & .219 & .057 & .190 & 3.850 & .000 \\
\hline & Chance off los & data & .344 & .050 & .325 & 6.835 & .000 \\
\hline & Challenging & & .137 & b.062 & .120 & 2.213 & .028 \\
\hline
\end{tabular}


Table 6: Challenges and threats of cloud accounting implementation in Bangladesh

\begin{tabular}{|l|c|c|}
\hline & N & $\%$ \\
\hline Lack of accessible high speed internet to be able to use C.A & 70 & $23.3 \%$ \\
\hline Never thought by people about using C.A & 23 & $7.7 \%$ \\
\hline Fear of accessible hackers & 34 & $11.3 \%$ \\
\hline Not so popular by the term C.A in BD & 109 & $36.3 \%$ \\
\hline Migration from traditional accounting is complex & 64 & $21.3 \%$ \\
\hline
\end{tabular}

\section{Conclusion}

Cloud-based accounting system, which is vital to the success or failure of business, is responsible for computing financial activities, with accounting transactions recording, data analysis activities, and financial performance helping decision-making by users. Being a developing country, to implement cloud accounting in Bangladesh, the application of cloud-based accounting should be encouraged by organizations, so service charges of cloud accounting should be reduced, cloud computing models including accounting software should be available at low implementation cost, different security measures should be applied in order to provide security for data, and services provided by cloud accounting and technology should be made simpler and easily accessible. Finally, proper training should be given to employees to access the application, resources or software to minimize time, cost and security threats. Through both qualitative and quantitative approaches, this paper assesses the knowledge of accounting practitioners, specially the opinion of accounting software users and fresh accounting graduates about prospects and challenges of cloud accounting implementation in Bangladesh. This paper has some limitations, given the lack of knowledge and lack of sufficient research in this related area in our country. The recommendation provided on the basis of the study may vary from country to country and regions. In Bangladesh, more research on this topic is needed. Further research may be on the practical situation and working progress of accounting practitioners who are using cloud accounting in their organization and personally.

\section{References}

Alimbudiono, R. S. (2020). Accounting Knowledge as a Contributing Intention on Improving Public Accounting Profession. Journal of Asian Finance, Economics and Business, 7(9), 801-809. doi: 10.13106/jafeb.2020.vol7.no9.801

Ali, Y., \& Thakur, U. (2017). An Empirical Study of "Awareness and Adoption of Cloud Based Accounting by Qualified Chartered
Accountants in Udaipur District of Rajasthan. Indian journal of Accounting (IJA), XLIX (2), 77-82.

Aryanti, C., \& Adhariani, D. (2020). Students' Perceptions and Expectation Gap on the Skills and Knowledge of Accounting Graduates. Journal of Asian Finance, Economics and Business, 7(9), 649-657. doi: 10.13106/jafeb.2020.vol7.no9.649

Dimitru, O., \& Matei, M. (2014). A New Paradigm for Accounting through Cloud Computing. Procedia Economics and Finance, $15,840-846$.

Ebenezer, E. E. S., Antwi, K. B. O., \& Kyei, M. E. (2014). Accounting in the Cloud: How Cloud Computing can Transform Businesses (The Ghanaian Concept). International Conference on Global Business, Economics, Finance and Social Sciences, 11(13).

Gupta, A. K., \& Gaur, P. (2018). Impacts of Cloud Computing on Accounting: Aids, Challenges and Its Future Growth. EPRA International Journal of Economic and Business Review, 6(3),40-54.

Islam, S., Kabir, M. H., Hossain, M. J., \& Chakraborty, A. (2015). Cloud Computing Technology in Bangladesh: A Framework of Social \& Economic Development. European Scientific Journal, 11(18), 393-410.

Khanom.T. (2017). Cloud Accounting: A Theoretical Overview. IOSR Journal of Business and Management, 19(6), 31-38.

Mell, P., \& Grance, T. (2009). Draft NIST Working Definition of Cloud Computing. National Institute of Standards and Technology, 53, 50.

Mell, P., \& Grance, T. (2011). The NIST Definition of Cloud Computing. National Institute of Standards and Technology, US Department of Commerce, Special Publication. 800-145.

Mohanty, A., \& Mishra, K. A. (2017). Benefits and Issues of Cloud Computing in Accounting. International Journal of Trend in Scientific Research and Development, 1(6), 283-288.

Shkurti, R., \& Muca, E. (2014). An Analysis of Cloud Computing and Its Role in Accounting Industry in Albania. Romanian Economic Business Review, 8(2), 219-229.

Sobhan, R. (2019). The concept of Cloud Accounting and its Adoption in Bangladesh. International Journal of Trend in Scientific Research and Development, 3(4), 1261-1267.

Tarmidi, M., Rasid, S. Z. A., Alrazia, B., \& Roni, R. A. (2014). Cloud computing awareness and adoption among accounting 
practitioners in Malaysia. Procedia - Social and Behavioral Sciences, 164, 569-574.

Tulsian, A. (2012). Why small business owners should take their accounting to the cloud. Information Technology - The Chartered Accountant, 979-982.
Yoo, S. K., \& Kim, B. Y. (2018). The Effective Factors of Cloud Computing Adoption Success in Organization. Journal of Asian Finance, Economics and Business, 6(1), 217-229. doi: 10.13106/jafeb.2019.vol6.no1.217 